\title{
Stabilized Sulphur Hexafluoride Microbubble-Based Contrast Agent
}

National Cancer Institute

\section{Source}

National Cancer Institute. Stabilized Sulphur Hexafluoride Microbubble-Based Contrast

Agent. NCl Thesaurus. Code C85471.

An injectable ultrasound contrast media formulation composed of microbubbles of stabilized sulphur hexafluoride (SF6) in sodium chloride solution. With stabilized sulphur hexafluoride microbubble-based contrast agent, ultrasound waves are scattered and reflected at the microbubble-blood interface during ultrasound imaging, thereby enhancing blood vessel visualization and the contrast between blood vessels and adjacent tissues. 